\title{
The Effects of 8-Weeks Aerobic Exercise Program on Blood Lipids and Cholesterol Profile of Smokers vs. Non Smokers
}

\author{
Akef Taifour ${ }^{1}$, Ahmad AL-Shishani ${ }^{1}$, Aman Khasawneh ${ }^{1}$, Ali AL-Nawaiseh ${ }^{1} \&$ Mohammed Bakeer $^{2}$ \\ ${ }^{1}$ Faculty of Physical Education and Sport Sciences, the Hashemite University, Zarqa, Jordan \\ ${ }^{2}$ Faculty of Physical Education, Jordanian University, Amman, Jordan \\ Correspondence: Aman Khasawneh, Faculty of Physical Education, the Hashemite University, Zarqa, Jordan. Tel: \\ 962-777-728-000. E-mail: amana752001@yahoo.com
}

\author{
Received: December 16, 2014 Accepted: January 7, 2015 Online Published: April 28, 2015 \\ doi:10.5539/ies.v8n5p131 URL: http://dx.doi.org/10.5539/ies.v8n5p131
}

\begin{abstract}
The aim of this study was to compare the effects of 8- week aerobic exercise program on blood lipids and cholesterol profile of smoker's VS non-smokers. A total of 34 male subjects (18 non-smokers and 16 smokers) took part in this study. Both groups were pre- and post tested in their blood-lipids and cholesterol profile before and after the 8-week aerobic training program. The results indicated that aerobic training improves blood lipids and cholesterol in both groups but the magnitude of improvement in both groups was not statistically different compared to the post-test scores. However, this study revealed that smokers can benefit from aerobic exercise as much as non-smokers. This indicates that smoking does not hinder smokers from improving their general health via regular aerobic exercise. It seems that longer than 8-week aerobic training program is needed to improve significantly blood-lipids and cholesterol profile in both smokers and non smokers.
\end{abstract}

Keywords: cholesterol profile, aerobic exercise, blood lipids

\section{Introduction}

\subsection{Introduce the Problem}

The positive health outcomes of exercise against hypo kinetic diseases (living a sedentary life style) on top factors of which comes cardio-vascular diseases are well established (Nieman, 1990).

In fact, exercise is considered a positive life style against some forms of lung cancer and heart disease. Thus exercise must be adopted as regular daily life style activity in any efforts to combat hypo kinetic diseases and cancer. However, the promotion of exercise as a regular daily activity must target those who need it most. In this regard, smokers especially chronic smokers are at higher risk for coronary artery diseases, the most deadly form of cardio-vascular diseases besides cancer (Suzuki, 2000; Hoyt, 2013) in Jordan and other industrial country $\mathrm{CHD}$ is the main cause of death.

The need for motivating smokers to participate in aerobic exercise (the best type of exercise that improves the functional capacity of the cardio vascular system) Tobacco smoking also contributes to a less-than-optimal improvement in cardiovascular fitness during a training program, this need is based on the following research finding and experts opinions:

1) Smokers in general and chronic smokers in particular tend to live a sedentary life style, an independent risk factor for cardio-vascular diseases (Wilmore \& Costill, 2004). In fact, it is reported that the risk of sedentary life style on cardio-vascular diseases equals the risks of smoking one pact cigarettes daily (McArdle, Katch, \& Katch, 2007). Chronic smoking is defined as smoking 25 cigarettes or more daily, just five cigarettes above one pact of cigarettes (Nieman, 1990).

2) Chronic smokers need to be educated regarding the importance of regular aerobic exercise. A positive life style change improves their quality of daily life despite their chronic smoking which they can't for a reason or another to stop and do without.

Based on the above, research on the response of smokers vs. non-smokers to aerobic exercise will be a step in the direction of encouraging smokers to exercise. Giving the evidence that while smoking reduces the aerobic performance it does not hinder the positive response of the cardio- vascular system to aerobic exercise. One of 
the major indexes of cardio-vascular health is blood lipids, cholesterol, and lipoprotein profile.

In exercise physiology terminology the word lipid is used to refer to fat and vice versa both are defined as being lass of organic compounds with very limited water solubility. Fats (lipids) are classified into three groups (simple (neutral) fat, compound fat, and derived fat), simple fats are two types (saturated fat-animal products, and unsaturated fat-plant origin). While compound fats come from (phospholipids, glycolipids, lipoproteins). Whereas cholesterol is the most popular forms of derived fat. However, cholesterol does not contain fatty acids but shares some of the chemical and physical properties of fat. Thus, from a dietary view point cholesterol is fat (Aruthr, 1983).

Cholesterol is essential to many body functions including building plasma membrane and serving as pre cursor in vitamin D and adrenal hormones synthesis besides sex hormones. From medical point of view the type of cholesterol is what makes cholesterol good or bad to health (Brouns, 1993).

Since fats (lipids) are not soluble in water, they must combine with special protein molecules to be transported in the blood after being absorbed from diet, mainly from diet high in saturated fat and trans- fatty acids. Thus, to reach the liver where fats are metabolized according to body needs, fats must combine with protein molecules to form lipoproteins. The density of lipoproteins depends on the protein percentage in lipoproteins that is: the higher percentage, the higher density and vice versa. (Appindex 1 describes the approximate composition of the four major groups of lipoproteins). Lipoproteins according to their density are classified as: (High density lipoproteins (HDL-C), Low density lipoproteins (LDL-C), and very low density lipoproteins (VLDL-C)). LDL-C is formed when the VLDL-C type gives up its TG content to body cells. LDL-C is high in cholesterol which makes it the bad type of cholesterol. In contrast: HDL-C is the good type. Medically speaking, high levels of both TG and LDL-C are negative risk factors in artery diseases, while HDL-C is positive protective factor against atherosclerosis as follows: (Brouns, 1993; Wilmore \& Costill, 2004)

- Triglyceride (T.G) is major content of VLDL-C in which LDL-C is formed when VLDL-C gives up its T.G content to body cells. LDL-C is the type of cholesterol that has a strong tendency to adhere to the inner livings of the arteries (the intima) thus, leading to atherosclerosis.

- As with serum cholesterol represents a composite of total blood cholesterol including HDL-C. Fat is absorbed and is circulated in blood as (T.G) in the form of circulating lipid particles HDL, VLDL, LDL chylomicrons or as free fatty acids. Cholesterol in general is either endogenous (produced mainly by the liver) or exogenous that reaches the liver through lipoproteins following a diet high in saturated fat. See Appendix 2 that describes healthy and unhealthy levels of blood-lipids and lipoproteins: (McArdle et al., 2007).

In fact, some subjects reported less craving for cigarettes during the 8- week exercise program, while others reported reduced numbers of smoked cigarettes during the exercise program of this study (West \& Schneider, 1987).

The need for the study is based on the very meager studies that investigated the response of smokers' VS non smoker to aerobic exercise programs using blood-lipids and lipoprotein profile index. Hence that most of the pervious investigations study the smoking phenomena from medical stand view as measure of aerobic exercise on major risk factors for cardio-vascular diseases. In other words, while the positive effects of exercise on blood-lipids and lipoprotein are established firmly among non-smokers. It is not clear whether smokers will respond the same as non- smokers to an aerobic exercise program, which is regarded as the best type of exercise to improve blood-lipids and lipoproteins profile.

In the same time, studies using smokers is the right choice of subjects because they are at higher risk of cardiovascular diseases.

\subsection{Limitations}

Alcohol consumption, diet and daily nutrition were not controlled by the investigators. However, the subjects were asked to fast for 16 hours in the pre and post blood test.

\subsection{Statement of the Problem}

Smoking tobacco is a practice that nearly everyone knows to be detrimental to general health in many ways.

Tobacco smoke contains up to $4 \%$ by volume carbon monoxide, by inhalation, the body absorbs some of this CO. The affinity of the hemoglobin to carbon monoxide is 200 to 300 times greater than to oxygen. The carbon monoxide in tobacco smoke reduces the oxygen carrying capacity of the blood by displacing some of the oxygen that ordinarily would be combined with the hemoglobin in the red blood cells. (Astrond, Rodahl, Dahl, \& 
Stromme, 2003; Sandra et al., 2002). Subjects who smoked 10-12 cigarettes per day had $4.9 \%$ carbon monoxide hemoglobin, those who smoked 15-25 cigarettes per day had 6.3\% and those who smoked 30-40 cigarettes per day had 9.3\%. Other studies have confirmed these findings (McArdle et al., 2007; Nieman, 1990). It may take 24 hours or more for the carbon monoxide content of blood to return to normal range (Pollock et al., 1984; Salhab, 1982; Shephard, 1994).

A blocking of $5 \%$ of the hemoglobin by $\mathrm{CO}$ will reduce the maximal oxygen uptake and performance (Rode \& Shephard, 1971). The difference in heart rate between smokers and non-smokers was greater which increased work load (Shephard, Stephens, Sutton, \& Mcpherson, 1998; Sanaa et al., 2013). Inhalation of smoke from a cigarette could fold raises in the airway resistance within seconds. A twice or triple more chronic swelling of the mucous membranes of the airways, leading to an increased airway resistance (Rode \& Shephard, 1971).

At rest when the pulmonary ventilation is less than 10 liter/min the increased airway resistance is not noticeable. However, when the demand on respiration is elevated (a need to increase the oxygen supply) the increased respiratory resistance caused by smoking may be noticeable. As a result reduced pulmonary ventilation capacity may cause a smaller volume of oxygen to reach the alveoli and an impaired gas exchange. This may in turn indicate impaired performance.

Physical activity is an adjunct treatment for the control of blood pressure, blood lipid, and obesity (Astrand \& Rodahl, 1977). Exercise is the most significant factor contributing to the health of the heart of the individual (Auhtur, 1983). Research in this field has conducted investigation about smoking effects from different stand view, most of the available data, study the smoking phenomena from the medical stand view as a risk factor associated with CHD e.g. a study by (Salhab, 1982) where he reported that in Jordan, during 1982-1986 (526 CHD case) have an emergency treatment in HRMC (Hussin Royal Medical City) for cardiac diseases and surgery center. Their ages were ranged between 27 and 85 year. $76 \%$ of those cases were smokers. Thus, to gain some insight into the basic relationship between physical performance and health and to foreshadow the role of smoking habit in Jordan, which it may play a significant role in impairing of both the related health fitness and physiological variables.

\subsection{Aerobic Exercise and Lipoproteins Profile Related Literature}

There are three powerful factors that affect blood-lipids and lipoproteins profile which are: (1. diet, 2. weight loss, 3. Exercise). The related literature in this regard can be summarized as follows:

(1) The reeducation in total cholesterol and LDL-C is dependent more on leanness and diet than on exercise (Durstine \& Thompson, 2000).

(2) Aerobic training is the most effective and powerful behavioral modification to increase HDL-C (Goldberg \& Elliot, 1985).

(3) The decrease in triglycerides (TG) concentration after the initiation of aerobic exercise is between (20-30\% and is dependent on initial concentration before starting aerobic exercise programs (Nieman, 1990).

(4) Aerobic exercise is the most effective approach to increase HDL-C profile with more improvement when concentration is low before aerobic training (Schwartz, 1987).

(5) The minimum energy expenditure required to improve blood lipoproteins profile is about (1000) Kcal at least per week with dose response relationships above this expenditure. That is: the more expenditure, the better in results (Tran, Weltman, Gloss, \& Mood, 1983).

(6) Better results are achieved if the exercise program was effective in weight reduction but the aerobic program is important and independent factor that leads to improvement in weight loss (Schwartz, 1987).

\subsection{Smoker and Exercise: Related Literature}

Smokers in general and chronic smoker in particular tend live a sedentary life style which is an independent risk factor for both heart diseases and cancer (Haskel, 1984).

Studies on the response of smokers to aerobic fitness are rather scarce and the reported studies are as follows:

One study reported significant improvement among female smokers in endurance performance following 12 -weeks aerobic exercise program. The same study revealed that the aerobic exercise program was very powerful incentive to quit smoking (Nieman, 1990).

In this regard, another study reported that 81 percent of men and 75 percent of women runners who had smoked cigarettes had stopped smoking (McArdle et al., 2007).

Further, the famous Framingham study reported the association between physical activities with fewer cigarettes 
smoked per day (Donnerbe, Keller, Wilson, \& Castelli, 1989).

Another study reported that users of smokeless-tobacco (chewed-sniffed) performed the same as non users of any form of tobacco use in physical fitness test including a cardio-vascular.

\subsection{Aim of the Study}

The main aim of this study was to answer the following question:

Does smoking reduce the adaptive response in blood-lipids and lipoproteins profile following 8-weeks of aerobic training compared to non smokers?

\section{Methodology}

\subsection{Study Design}

A quasi experimental, pre and posttest parameter in physiological responses (lipid profile) were conducted using a sample of intact groups which was used in this study.

\subsection{Population and Sample}

Total of (34) middle aged sedentary male subjects (18 non-smokers and 16 smokers) took part in this study and they were divided into two group. Table 1 describes the general statistic of age and physical characteristics of the subjects (body height and body weight).

Table 1. Descriptive statistics of some selected characteristics and body composition parameters

\begin{tabular}{lllllll}
\hline Source & \multicolumn{1}{l}{ Age } & \multicolumn{3}{c}{ Body Height $(\mathrm{cm})$} & \multicolumn{2}{c}{ Body weight $(\mathrm{kg})$} \\
\cline { 2 - 7 } & Mean & SD & Mean & SD & Mean & SD \\
\hline Smoker & 52.9 & 3.84 & 174.1 & 6.09 & 91.8 & 16.00 \\
Non Smoker & 51.9 & 3.41 & 174.4 & 5.60 & 88.6 & 13.06 \\
Pre/sig & NS & & NS & & NS & \\
\hline
\end{tabular}

\subsection{The Program}

Both groups were pre- and post tested in their blood-lipids and cholesterol profile before and after the 8 -week aerobic training program. The 8 -week aerobic exercise program employed in this study consisted of the following parts.

A) 12- Minutes of continues walk-Jog part.

B) An aerobic circuit training part that employed the following aerobic drills (stations).

- Jumping jacks in place for (2) Minutes duration.

- Rebound double leg rope skipping for one minute.

- Stepping up and down a $30 \mathrm{~cm}$ high box for (30) minutes with (20) repetition per minute cadence observed using a metronome set on (80) cadence [(4) counts for each repetition].

- Jumping in place with knees up to chest for one minute.

- Running up and down (20) stairs of a specially designed wooden stair platform repeated twice in a row within a minute.

- A polar device was employed to monitor heart rate to ensure the training intensity of (60-80) percent of heart rate reserve (HRR) as calculated using the karvonen formula.

The polar device was employed twice as follows:

A) In the end of the (12) minute walk-Jog part of the aerobic program.

B) In the end of the last station of the circular aerobic program (Running up and down the (20) stair platform twice).

- All subjects started treatment with the (12) minute part of the aerobic program. A five minute rest interval separated the walk-jog part from the circular aerobic training part, and (30) seconds rest intervals were allowed between the successive stations of the circular training part of the aerobic program employed in this study. 
- The training program extended for (8) weeks with (3) training sessions a week frequency.

- All subjects were required to sign a written consent form and to obtain medical clearance before the start of the aerobic exercise program.

\subsection{Sampling Procedures}

- All subjects were introduced to the components of the training program and were allowed to practice both parts of the training program in the week before starting the program to quaint subjects with the physical demands and correct excision of the drills in the circuit aerobic program.

- All training sessions were preceded with 10 minute warm up that employed stretching and brisk walking.

- All training sessions ended with (5) minute brisk walking.

- Verbal motivating remarks were employed during the execution of the circuit aerobic training part of the exercise treatment protocol employed in this study.

\subsection{Measures and Covariates}

The parameters evaluated pre- and post the aerobic program treatment which has relevance to the aims of the study included the following blood- lipids profile constituents.

- Plasma total cholesterol level.

- $\quad$ LDL-C concentration.

- HDL-C concentration.

- TG. Triglycerides concentration.

These parameters were measured in private medical laboratory pre and post the aerobic exercise program. Appendix 1 describes the criteria employed in determining the normal and abnormal levels of blood lipids concentrations as recommended by the ACSM (American College of Sports Medicine) And AHA (American Heart Association) (9, 16).

\subsection{Data Analysis}

Statistical analysis was performed using SPSS. Means, standard deviations was used to achieve the first research question, while Analysis of Multivariate test (MANOVA) was used to achieve the second research question.

\section{Result}

As was stated earlier, the aim of this study was to investigate the effects of (8) week aerobic exercise program on blood lipids profile of smokers compared to non-smokers.

Table 2 showed the result of t-test of some selected physiological parameters of blood lipid profile of smokers compared to non- smokers.

Table 2. T-test of physiological parameters of blood lipid profile of smokers compared to non- smokers.

\begin{tabular}{llccccccc}
\hline Source & \multicolumn{2}{c}{ Pre-test } & \multicolumn{2}{c}{ Post-test } & Pre vs. Post & \multicolumn{2}{c}{ Smokers vs. Non smoker } \\
\hline Total cholesterol & & Mean & SD & Mean & SD & Sig & Pre/Sig & Post/Sig \\
\cline { 2 - 9 } & Smoker & 213.7 & 41.60 & 203.6 & 47.60 & $\mathrm{P}<0.05$ & Ns & Ns \\
& No smoker & 200.9 & 42.70 & 197.5 & 34.60 & Ns & & Ns \\
HDL-C (mg/dl) & Smoker & 35.9 & 8.52 & 39.0 & 7.23 & $\mathrm{P}<0.05$ & Ns & \\
& No smoker & 40.9 & 9.25 & 41.7 & 10.40 & Ns & & Ns \\
LDL-C (mg/dl) & Smoker & 127.5 & 48.00 & 123.4 & 55.20 & Ns & Ns & \\
\multirow{3}{*}{ Triglycerides (mg/dl) } & No smoker & 123.4 & 45.40 & 121.8 & 49.70 & Ns & & Ns \\
& Smoker & 267.6 & 173.0 & 212.6 & 118.2 & P $<0.05$ & Ns & \\
& No smoker & 248.9 & 200.0 & 207.8 & 141.1 & Ns & & \\
\hline
\end{tabular}

The table showed that blood lipids profile responded favorably to the aerobic training program. No significant statistical difference was observed between smokers and non-smokers in levels of blood lipids $(p<0.05)$ tested in 
this study. This study suggests that even though smokers can improve their blood lipids through training, they always will have a lower level of lipids improvement than would be the case if they did not smoke.

The magnitude of improvement in T.G level was better in smokers' (94.6 mg LDL) reduction in smokers compared to $(48.9 \mathrm{mg} / \mathrm{Dl})$ reduction in non smokers. While the magnitude of improvement in HDL-C was also higher among smokers being $(3.1 \mathrm{mg} / \mathrm{Dl})$ compared to only $(0.8 \mathrm{mg} / \mathrm{Dl})$ in non smokers. Moreover, total cholesterol was reduced more in smokers by $(10.1 \mathrm{mg} / \mathrm{Dl})$ compared to reduction of $(3.4 \mathrm{mg} / \mathrm{Dl})$ in non smokers. However, as was mentioned above, the magnitude of post-test change was not statistically significant $(\mathrm{p}<0.05)$ in both groups compared to pre-test scores.

The better improvement in T. G and HDL-C levels among smokers compared to non smokers can be explained on the basis of higher pre-test scores of smokers in both T. G and HDL-C values which goes along with the rule of thumb that states "those with higher pre treatment scores of T.G will lose more compared with those with lower scores, on the same time, those with a lower score in HDL-C will respond better than those with lower scores" (Trans \& Weltman, 1985).

\section{Conclusions}

The adoptive response of blood- lipids and cholesterol- lipoproteins profile was not statistically different among smokers compared to non-smokers following 8-weeks of aerobic training. That is, the benefits of aerobic exercise are independent of smoking status.

The improvement in blood lipids-lipoproteins profile in both groups-smokers and non- smokers was not statistically different from the pre-test scores, yet better in general. The explanation might be that significant improvement in the profile needs longer than 8-weeks duration aerobic exercise program.

\section{Recommendations}

- Based on the results and conclusions of this study the principal recommendation is to target smokers as subjects for research in the positive effects of aerobic exercise VS the negative effects of both smoking and sedentary life style among chronic smokers who can't stop smoking for a reason or another.

- Exercise must be promoted and motivated among smokers according to the following motto: The search for the perfect solution for smoking cessation projects "quit smoking all together" must not tinder the quest for the "Good" solution. (Exercise) since Good is better than worse, that is sedentary life style.

- It might be a "good idea" to put lattes on cigarette packs that read: "Exercise is bad for your smoking habit.

\section{References}

Albrecht, A. E., Marcus, B. H., Roberts, M., Forman, D., \& Parisi, A. F. (1998). Effects of Smoking Cessation on Exercise Performance in Female Smokers Participating in Exercise Training. American Journal of cardiology, 82(8), 950-955. http://dx.doi.org/10.1016/S0002-9149(98)00511-6

Aruthr, S. (1983). Exercise and Risk of Coronary Heart Disease. American Academy Physical Education Papers. Human Kinetics Publishers.

Astrand, P., \& Rodahl, K. (1977). Textbook of Work physiology. McGraw-Hill Book Company.

Astrand, P., Rodahl, K., Dahl, H., \& Stromme, S. (2003). Textbook of Wok Physiology: Physiological Bases of Exercise (4th ed., pp. 447-449). Human Kinetics.

Bahrke, M., Baur, T., \& Poland, D. (1988). Performance of Habitual Smokeless Jobaco Users on the US Army Soldier Physical Fitness. (The APFT-test), JEST: 12-15.

Brouns, F. (1993). Nutritional Needs of Athlete. John Wiley and Sons, England.

Donnerberg, A., Keller, B., Wilson, W., \& Castelli, W. (1989). Leisure Time physical Activity in the Framingham off-Spring Study. American Journal of Epidemiology, 129, 76-88.

Durstine, J., \& Thompson, R. (2000). Exercise Modulates Blood Lipids and Lipoproteins. Exercise and Sport Science Reviews, 4, 7-12.

Goldberg, L., \& Elliot, D. (1985). The Effect of Physical Activity on Lipid and Lipoprotein Levels. Medicine Clinic North America, 69, 41-55.

Haskel, W. (1984). Exercise Induced Changes in Plasma Lipids and Lipoproteins. Preventive Medicine, 13, 23-26. http://dx.doi.org/10.1016/0091-7435(84)90038-0

Howley, T., \& Franks, B. (2003). Health Fitness Instructors Handbook. Human kinetics Publishers. 
Hoyt, L. (2013). Cigarette Smoking: Nicotine, Carbon Monoxide, and the Physiological Effects on Exercise Responses. Sport Science Review, 22, 1-2. http://dx.doi.org/10.2478/ssr-2013-0001

McArdle, W., Katch, F., \& Katch, V. (2007). Exercise Physiology: Energy, Nutrition and Human Performance (6th ed.). Lippincott Williams and Wilkins.

Nieman, D. (1990). Fitness and sports medicine, an introduction. Bull publishing company.

Pollock, M. et al. (1984). Exercise in Health and Disease, Evaluation and Prescription for Prevention and Rehabilitation. W.B. Saunders Company.

Rode, R., \& Shephard, R. (1971). The Influence of Cigarette Smoking Upon the Work of Breathing in Near-Maximal Exercise. Medicine and Science in Sports, 3, 51-55.

Salhab, A. (1982). A Study on Smoking in Jordan. DERASAT, 4, 257-268.

Sanaa, K. M., Yanal, A. S., Pana, B. A., Faisal, A. K., Loai, A. Z., \& Christian, C. (2013). Youth Attitudes Towards Water Pipe Smoking in Amman Jordan. Jordan Medicine Journal, 47(1), 35-43. http://dx.doi.org/10.12816/0001067

Sandra, K., Martin, P., Boxtel, J., Monigu, W., Verschuren, M., \& Lenre, L. (2002). Cigarette Smoking and Alcohol Consumption in Relation to Cognitive Performance in Middle Age. American Journal of Epidemiology, 156, 10. http://dx.doi.org/10.1093/aje/kwf135

Schwartz, R. S. (1987). The Independent Effects of Dietary Weight Loss and Aerobic Exercise Training on High Density Lipoprotein and Apo lipoprotein. American Journal of Concentration, Metabolism, 36, 165-171. http://dx.doi.org/10.1016/0026-0495(87)90012-6

Shephard, R. (1994). Aerobic Fitness and Health. Human Kinetics Publishers.

Shephard, R., Stephens, T., Sutton, J., \& McPherson, B. (1998). Exercise, Fitness and Health Consensus of Current Knowledge. Human Kinetics Publisher.

Suzuki, M. (2000). Exercise and Nutrition: Physical Activity and Lifestyle Related Disease. Nippon-Rinsho Sha, 53-60.

Tran, Z., \& Weltman, A. (1985). Differential Effects of Exercise on Serum Lipids and Lipoprotein Levels Seen with Body Weight Changes. J.A.M.A., 254, 919-924. http://dx.doi.org/10.1001/jama.1985.03360070057023

Trans, Z., Weltman, A., Glass, G., \& Mood, D. (1983). The Effects of Exercise on Blood-Lipids and Lipoproteins: A Meta Analysis of Studies. Medicine Sciences of Sport and Exercise, 15, 393-402. http://dx.doi.org/10.1111/j.1360-0443.1987.tb01496.x

West, R., \& Schneider, N. (1987). Craving for Cigarettes. British Journal Addiction, 82(4), 407-415.

Wilmore, J., \& Costill, D. (2004). Physiology of Sport and Exercise (3rd ed.). Human kinetics.

\section{Appendix A}

Approximate composition of blood lipoproteins

\begin{tabular}{|c|c|c|c|c|}
\hline & & & & \\
Composition & HDL-C & LDL- C & V-LDL & Chilomictions \\
\hline Protein \% & $45-55$ & 25 & $5-15$ & $0.5-1.0$ \\
\hline Lipid \% & 50 & 75 & 95 & 99 \\
\hline Cholesterol \% & 18 & & & \\
\hline & & $40-45$ & $10-20$ & $2-5$ \\
\hline Triglycerides & 2 & & & 85 \\
\hline Phospholipids & 30 & $5-10$ & $50-70$ & $3-6$ \\
\hline
\end{tabular}




\section{Appendix B}

Describes the criteria employed in determining the normal and abnormal levels of blood lipids concentrations as recommended by the ACSM

\begin{tabular}{|c|c|c|c|c|c|c|c|}
\hline \multicolumn{2}{|c|}{ Total cholesterol (mg/DL) } & \multicolumn{2}{|c|}{ LDL-C (mg/DL) } & \multicolumn{2}{|c|}{ HDL-C (mg/DL) } & \multicolumn{2}{|l|}{ TG-mg-Dl } \\
\hline $\begin{array}{l}\text { Less than } \\
200\end{array}$ & Excellent & $\begin{array}{l}\text { Less than } \\
(100) \mathrm{mg}\end{array}$ & Excellent & $\begin{array}{l}60 \text { and } \\
\text { up }\end{array}$ & Excellent & $\begin{array}{l}\text { Less than } \\
150\end{array}$ & Excellent \\
\hline $239-200$ & Border line & $100-129$ & Very good & $40-59$ & Good & $150-159$ & Border line \\
\hline \multirow[t]{3}{*}{$\begin{array}{l}240 \text { and } \\
\text { up }\end{array}$} & $\begin{array}{l}\text { High } \\
\text { (Dangerous) }\end{array}$ & $130-159$ & Border line & $\begin{array}{l}\text { Less } \\
\text { than } 40\end{array}$ & $\begin{array}{l}\text { Poor } \\
\text { dangerous }\end{array}$ & $499-200$ & $\begin{array}{l}\text { High } \\
\text { dangerous }\end{array}$ \\
\hline & & $160-189$ & $\begin{array}{l}\text { High } \\
\text { (dangerous) }\end{array}$ & & & & \\
\hline & & 190 and up & $\begin{array}{l}\text { Very high very } \\
\text { dangerous }\end{array}$ & & & & \\
\hline
\end{tabular}

\section{Copyrights}

Copyright for this article is retained by the author(s), with first publication rights granted to the journal.

This is an open-access article distributed under the terms and conditions of the Creative Commons Attribution license (http://creativecommons.org/licenses/by/3.0/). 